\title{
MATTHIAS WISSMANN
}

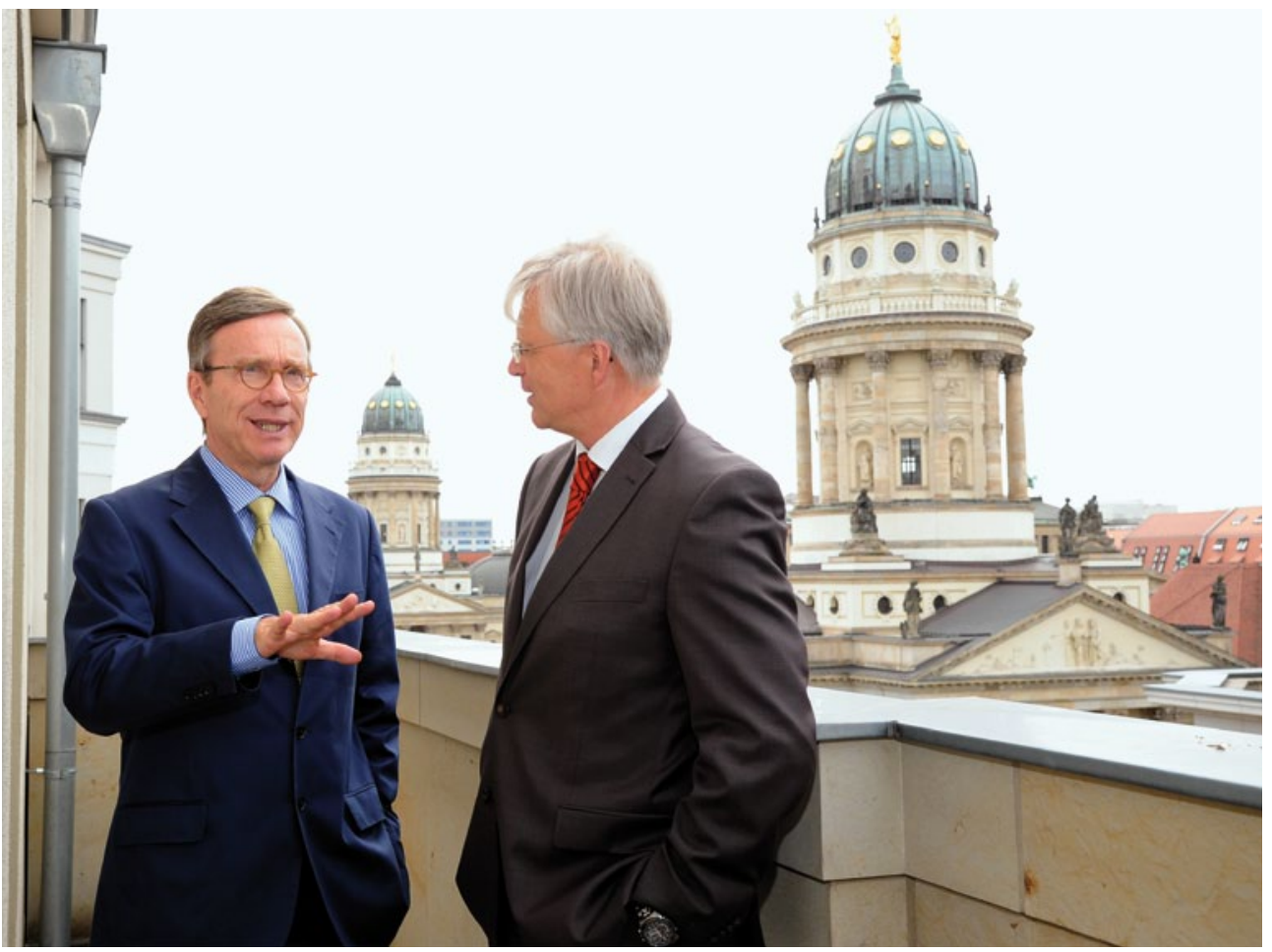

Matthias Wissmann vom VDA war sowohl Bundesminister für Verkehr als auch für Forschung; mit 31 Jahren Politikerkarriere ist er Kommunikationsvollprofi. Wissmann: „Die deutsche Automobilindustrie ist Benchmark für den Weltmarkt. In zehn Jahren möchten wir auch noch dort stehen."

BILD @ Elke A. Jung-Wolff

\section{„NUR TOTE FISCHE SCHWIMMEN MIT DEM STROM“}

Matthias Wissmann, Präsident des Verbandes der Automobilindustrie (VDA) verkörpert keineswegs den vollgasfesten Autofreak. Wissmann liebt den Flügeltürer Mercedes $300 \mathrm{SL}$ - ein für die damalige Zeit visionäres Fahrzeug. Für den HC Ludwigsburg spielte er jahrelang in der Bundesliga Hockey. Vision und Ausdauer, zwei Eigenschaften, die den Menschen Wissmann heute auszeichnen. Als es üblich war, links abzubiegen, ging Wissmann rechts. Als in seiner Studentenzeit, die 68er hat er gerade noch mit erlebt, der Mainstream zu Sit-ins strömte, sagte sich Wissmann: „Nur tote Fische schwimmen mit dem Strom" - und trat der CDU bei.

Der 1949 in Ludwigsburg geborene Wissmann studierte in Tübingen und Bonn Jura und VWL. Als oberster Autolobbyist, der VDA vertritt die Interessen von knapp 600 Mitgliedsunternehmen, sieht Wissmann die Förderung einer sauberen und sicheren Zukunftsmobilität als Hauptaufgabe. Saubere Mobilität lebt er selbst vor - wann immer möglich, fährt er mit dem Fahrrad von seinem Wohnort in Berlin Mitte ins VDA-Gebäude in der Behrenstraße.

2007, als Wissmann das Steuer des VDA übernahm, lief es wirtschaftlich gerade noch gut. Dann kamen der freie Fall und die anschließende sagenhafte Auferstehung. Man nimmt es dem Kommunikationsprofi ab, wenn er sagt: „Dass wir so schnell aus der Krise kommen, hat niemand erwartet." Sicher wird der Automobilindustrie 2012 der Wind härter um die
Ohren wehen als im Vorjahr, dennoch schneidet gerade die deutsche Vorzeigebranche deutlich besser ab als ihre europäischen Branchenkollegen. „Weil die deutsche Automobilindustrie auf dem Weltmarkt eine sehr gute Position hat. Wir sind global aufgestellt. Wir versuchen, zwischen den vier wichtigsten Weltregionen Europa, Nordamerika, Asien und Lateinamerika eine Balance zu finden“, begründet Wissmann die Stärke.

\section{„WIR MÜSSEN AN DER KOSTENSEITE ARBEITEN“}

In allen zehn Pkw-Marktsegmenten hat die deutsche Autoindustrie im Schnitt niedrigere $\mathrm{CO}_{2}$-Emissionen als die Konkurrenz. Kein Wunder, dass für Wissmann Know-how-Schutz eine hohe Priorität genießt. „So haben wir uns in der nationalen Plattform Elektromobilität gemeinsam entschlossen, das Thema Energiespeicher im engen Schulterschluss von Forschungsinstituten, Hochschulen und Automobilindustrie hier in Deutschland massiv voranzutreiben." Und Wissmann kennt die Preissensibilität der Verbraucher im Volumensegment. „Die Gesamtkostenbilanz eines Elektrofahrzeugs liegt über einen Zeitraum von drei bis vier Jahren immer noch 10.000 bis 12.000 Euro über der eines vergleichbaren Autos mit Verbrennungsmotor. Zur Durchdringung der Märkte mit alternativ angetriebenen Fahrzeugen müssen wir an der Kostenseite noch gewaltig arbeiten.“

Roland Schedel 